\title{
Evaluation of availability, accessibility and prescribing pattern of medicines in the Islamic Republic of Iran
}

A.M. Cheraghali, ${ }^{1,2}$ S. Nikfar, ${ }^{3}$ Y. Behmanesh, ${ }^{3}$ V. Rahimi, ${ }^{4}$ F. Habibipour, ${ }^{5}$ R. Tirdad, ${ }^{6}$ A. Asadi $^{3}$ and A. Bahrami ${ }^{7}$

$$
\begin{aligned}
& \text { تقييم توافُر وإتاحة ووصف الأدوية في بمهورية إيران الإسلامية }
\end{aligned}
$$

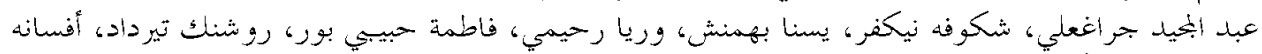

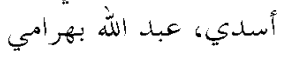

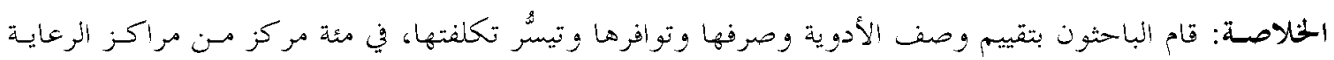

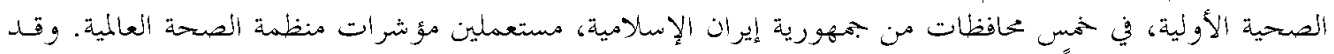

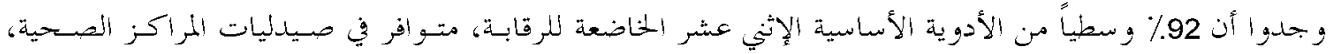

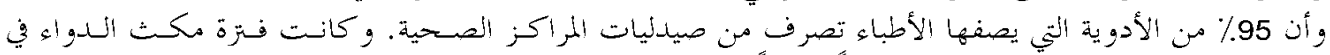

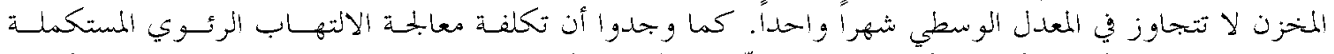

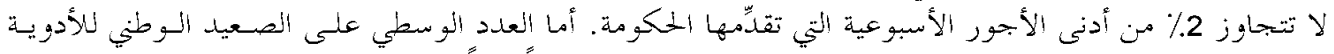

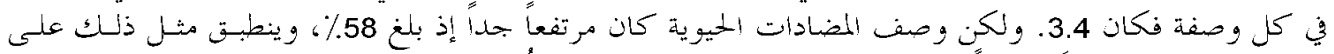

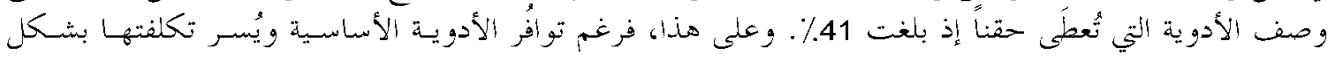

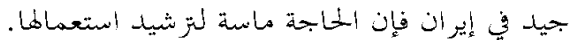

ABSTRACT Prescribing, dispensing, availability and affordability of drugs were evaluated in 100 primary health care centres in 5 provinces of the Islamic Republic of Iran using WHO indicators. On average, 92\% of the 12 essential drugs monitored were available in the health centre pharmacies and $95 \%$ of the drugs prescribed by the physician were dispensed by the health centre pharmacy. The stock-out duration was less than 1 month on average. A complete treatment for pneumonia cost only $2 \%$ of the lowest weekly government salary. The national average number of drugs per prescription was 3.4. Prescription of antibiotics and injectable drugs was very high ( $58 \%$ and $41 \%$ respectively). Although availability and affordability of essential drugs is good in this country, rational use of drugs needs to be emphasized.

\begin{abstract}
Evaluation de la disponibilité, de l'accessibilité et de la prescription des médicaments en République islamique d'Iran

RESUME La prescription, la délivrance, la disponibilité et l'accessibilité économique des médicaments ont été évaluées dans 100 centres de soins de santé primaires de cinq provinces de la République islamique d'Iran à l'aide des indicateurs de l'OMS. En moyenne, $92 \%$ des 12 médicaments essentiels étudiés étaient disponibles dans les pharmacies des centres de santé et $95 \%$ des médicaments prescrits par le médecin étaient délivrés par la pharmacie du centre de santé. La durée des ruptures de stock était inférieure à un mois en moyenne. Le coût d'un traitement complet pour la pneumonie ne représente que $2 \%$ du salaire hebdomadaire le plus bas dans l'administration. Le nombre moyen de médicaments par ordonnance au niveau national était de 3,4. La prescription d'antibiotiques et de médicaments injectables était très élevée (58\% et $41 \%$ respectivement). Bien que la disponibilité et l'accessibilité économique des médicaments essentiels soient bonnes dans ce pays, il est nécessaire de promouvoir l'usage rationnel des médicaments.
\end{abstract}

${ }^{1}$ Department of Pharmacology, Baqyyatallah Medical Science University, Tehran, Islamic Republic of Iran. ${ }^{2}$ Food and Drug Control Laboratories, Ministry of Health and Medical Education, Tehran, Islamic Republic of Iran.

Food and Drug Departments, ${ }^{3}$ Tehran; ${ }^{4}$ Kermanshah; ${ }^{5}$ Fars; ${ }^{6}$ Khozestan; ${ }^{7}$ Khorasan, Islamic Republic of Iran. Received: 18/09/02; accepted: 29/09/03

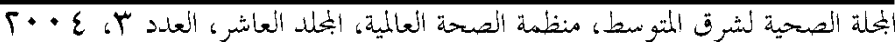




\section{Introduction}

In the last two decades, the main strategies of the health sector in the Islamic Republic of Iran have been a focus on primary health care and health centres, universal insurance coverage, implementing a referral system, improving quality of life, population control and eradication of communicable diseases.

As in many other countries, the Iranian Ministry of Health (MOH) has a mission to provide access to a sufficient quantity of safe, effective and high quality drugs that are affordable for the whole population. After 1979, a full generic-based drug system was adopted, with development of a national drug policy [1]. The Iranian national drug policy is based on generic medicines, local production of generic drugs and vaccines, price control, a national industry, herbal medicine, self-sufficiency in vaccine production, licensing for locally produced and imported pharmaceutical and biological products and active good manufacturing practice (GMP) inspection.

A national drugs list has been adopted, and essential drug production is government-subsidized in order to increase the availability and affordability of drugs. Drug procurement is also centralized to 1 stateowned company that is responsible for procuring most of the imported drugs and to 2 other semi-private companies as alternatives. At present, both national regulatory and national control laboratories are well developed and functioning. Essential drugs are estimated to be available and affordable for more than $90 \%$ of the population.

Despite these successes, there is some evidence of poor prescribing habits by physicians, including irrational use of drugs, high numbers of drugs per prescription and high use of injectable formulations and antibiotics.
The pharmaceutical sector is complex because it involves several stakeholders and government agencies. There is a need for systematic monitoring of the impact of country strategies and activities on access and use of medicines. In its Operational package for monitoring and assessing the pharmaceutical situation in countries [2] WHO has developed 3 levels of indicators and corresponding data collection tools. Level I indicators provide a rapid means of obtaining information on the existing infrastructure and key processes of each component of the pharmaceutical sector. Level II indicators provide systematic data to describe the degree of attainment of the national policy objectives on access and rational use of quality drugs. Our study focused on the level II indicators, which were designed to provide countries with a practical and feasible tool to develop systems for monitoring the pharmaceutical situation in their country [2]. It details methods for regularly monitoring and assessing national drug policies while minimizing the investment of time, people and money. It is intended to demonstrate that, in the long term, regular monitoring is not difficult and can be done in a cost-efficient manner. It also encourages countries to allocate a portion of their budget for project grants to support monitoring and evaluation of the results of their pharmaceutical policy and the development of a plan of action $[2,3]$.

The Iranian $\mathrm{MOH}$ dedicates considerable financial and human resources to monitoring the efficiency of the pharmaceutical sector in terms of rational use of safe drugs. The objectives of the present study were to evaluate physician prescribing patterns, pharmacy dispensing patterns, the availability and affordability of medicines, the quality of drug supply, and the availabil-

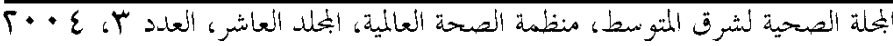


ity of information in public health centres in the Islamic Republic of Iran using WHO tools [2] and, based on the results of the evaluation, to propose possible interventions for the improvement of the pharmaceutical sector.

\section{Methods}

\section{Indicators}

The study methods followed the WHO Essential Drug Monitoring programme guidelines for monitoring and assessing the pharmaceutical situation in countries [2]. The following indicators were used. Availability and storage indicators:

- Percentage of essential drugs available at health centres

- Percentage of drugs prescribed that are dispensed at health centres

- Percentage of premises stocking 1 or more drugs that were past their expiry date

- Percentage of drugs adequately stored (storage scored 0-11)

- Mean stock-out duration (annual number of days on which a drug was not available in the pharmacy)

- Affordability of drugs (ratio of treatment cost of pneumonia to the lowest government weekly salary).

Prescribing indicators:

- Mean number of drugs per prescription

- Percentage of prescriptions with at least 1 antibiotic

- Percentage of prescriptions with at least 1 injectable drug

- Percentage of prescriptions following standard treatment guidelines for 3 common conditions (uncomplicated diarrhoea, acute/upper respiratory tract infection and mild to moderate pneumonia).
Pharmacy dispensing indicators:

- Percentage of prescriptions where drug labelling was adequate (i.e. drug name, dosage and expiry date)

- Percentage of prescriptions where patient knowledge was adequate (i.e. patient was able to recognize the drug, its indication and use).

Information availability indicators:

- Percentage of facilities with standard treatment guidelines available

- Percentage of facilities with essential drugs list available.

Based on Iranian consumption patterns, a list of 12 essential medicines were selected for this survey from the Iranian national drugs list. Items were those used mainly in primary health care to treat common diseases and included oral rehydration salts, co-trimoxazole, penicillin, acetaminophen, ferrous sulfate, folic acid, mebendazole, tetracycline (eye ointment), povidone iodine, clotrimazole, antacid and paediatric drops of multivitamins or vitamins A and D.

\section{Data collection}

Five regions were selected according to their geographical distribution and to the local availability of qualified personnel who could conduct the evaluation. The chosen provinces were Fars, Tehran, Khorasan, Khuzestan and Kermanshah. In each province, 20 public primary health centres were randomly chosen. The choice was nevertheless restricted to centres where a pharmacy was operative.

In each province, a responsible investigator was named. These investigators held an introductory meeting in order to prepare the investigation and define the necessary procedures. The actual evaluation was then performed by personnel chosen in the province. Several other persons were therefore involved in the survey in the field.

البحلة الصحية لشرق المتونط، منظمة الصحة العالمية، ابخلد العاشر، العلدد ب، ع • •؟ 
Data were collected during the year 2001, assembled in the provinces and then forwarded to $\mathrm{MOH}$ in Tehran for review and consolidation. During a 2-day meeting in June 2002, the person in charge of each region, representatives of $\mathrm{MOH}$ and a WHO consultant analysed and discussed these results and developed recommendations for improving the pharmaceutical sector in the Islamic Republic of Iran.

\section{Results}

\section{Accessibility of drugs}

Table 1 shows the results of the accessibility indicators. On average, $92 \%$ of the 12 items monitored were available in the health centre pharmacies. Only in 3 facilities out of 100 was the availability less than $60 \%$. On average $95 \%$ of the drugs prescribed by the physician were dispensed by the health centre pharmacy. The stock-out duration (i.e. the annual number of days during which a drug from the list was unavailable in the pharmacy) was 29 days on average.
In one province (Khozestan) it was more than 2 months.

The storage indicators showed only $2 /$ 100 centres had more than 1 expired drug on their shelves and the average score for quality of storage was 8 on a scale from 0 to 11 (Table 1).

Due to price control policy in the Islamic Republic of Iran, prices of medicines are identical throughout the country. A complete course of treatment for pneumonia costs on average $2 \%$ of the lowest weekly government salary.

\section{Physicians' prescribing practices}

The national average number of drugs per prescription was 3.4 (ranging from 2.8 in Tehran province to 3.8 in Khorasan) (Table 2). In $19 \%$ of the facilities evaluated, the number of drugs per prescription was more than 4.0. The number of prescriptions containing an antibiotic was $58 \%$ on average (ranging across provinces from $48 \%$ in Fars to $66 \%$ in Tehran). The number of prescriptions containing an injectable

\begin{tabular}{|c|c|c|c|c|c|c|}
\hline Indicator & Khorasan & Tehran & Fars & Khozestan & Kermanshah & $\begin{array}{l}\text { National } \\
\text { average }\end{array}$ \\
\hline Drugs available at facility (\%) & 93 & 100 & 88 & 86 & 94 & 92 \\
\hline $\begin{array}{l}\text { Drugs prescribed that are } \\
\text { dispensed at facility (\%) }\end{array}$ & 97 & 95 & 94 & 93 & 95 & 95 \\
\hline Stock-out duration (days) ${ }^{a}$ & 20 & 3 & 32 & 69 & 22 & 29 \\
\hline Facilities with expired drugs (\%) & 2 & 0 & 1 & 0.4 & 0 & 0.7 \\
\hline Adequacy of storage (score) ${ }^{\mathrm{b}}$ & 7 & 9 & 9 & 10 & 8 & 8 \\
\hline Affordability of drugs $(\%)^{c}$ & & & & & & 2 \\
\hline
\end{tabular}

${ }^{a}$ Annual number of days on which a key drug was not available in the pharmacy.

${ }^{b}$ Maximum score 11.

${ }^{c}$ Ratio of treatment cost of pneumonia to the lowest government weekly salary. Prices of the medicines are the same across the country.

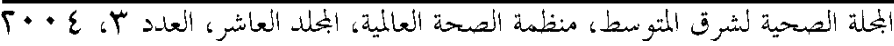




\begin{tabular}{|c|c|c|c|c|c|c|}
\hline Indicator & Khorasan & Tehran & Fars & Khozestan & Kermanshah & $\begin{array}{l}\text { National } \\
\text { average }\end{array}$ \\
\hline $\begin{array}{l}\text { Mean no. of drugs per } \\
\text { prescription }\end{array}$ & 3.8 & 2.8 & 3.4 & 3.7 & 3.2 & 3.4 \\
\hline $\begin{array}{l}\text { Prescriptions with 1+ } \\
\text { antibiotic (\%) }\end{array}$ & 58 & 66 & 48 & 64 & 58 & 58 \\
\hline $\begin{array}{l}\text { Prescriptions with } 1+ \\
\text { injectable drug (\%) }\end{array}$ & 42 & 29 & 49 & 50 & 35 & 41 \\
\hline $\begin{array}{l}\text { Prescriptions following } \\
\text { STG for: } \\
\text { Uncomplicated }\end{array}$ & & & & & & \\
\hline $\begin{array}{l}\text { Uncomplicated } \\
\text { diarrhoea (\%) }\end{array}$ & 5 & 26 & 20 & 0 & 8 & 12 \\
\hline $\begin{array}{l}\text { Acute URTI (\%) } \\
\text { Mild to moderate }\end{array}$ & 31 & 19 & 36 & 13 & 21 & 23 \\
\hline pneumonia $(\%)^{a}$ & 51 & 83 & 44 & 71 & 54 & 66 \\
\hline
\end{tabular}

$S T G=$ standard treatment guidelines .

$U R T I=$ acute/upper respiratory tract infection.

anly 1 antibiotic on prescription.

drug was $41 \%$ on average, with a considerable variation among centres (ranging between $3 \%$ and $80 \%$ ).

Adherence of prescribers to standard treatment guidelines showed only $12 \%$ of prescriptions on average followed national guidelines for treating uncomplicated diarrhoea (range across provinces $0 \%$ to $26 \%) ; 23 \%$ for acute upper respiratory tract infection (range $13 \%$ to $36 \%$ ); and $66 \%$ for mild to moderate pneumonia (range $51 \%$ to $83 \%$ ) (Table 2).

Table 3 shows in more detail the prescribing habits in surveyed health centres for treating uncomplicated diarrhoea, acute upper respiratory tract infection and mild/ moderate pneumonia. In addition to oral rehydration salts (in $57 \%$ of cases), prescribers prescribed antibiotics and antispasmodics in $64 \%$ and $59 \%$ of cases of diarrhoea, respectively. Although patients received antibiotics for treatment of acute upper respiratory tract infection in $77 \%$ of cases, prescribing cough and cold medicines were also common (in $78 \%$ of cases). The most used antibiotics for treating mild/moderate pneumonia was amoxicillin, followed by procaine penicillin. However, in $77 \%$ of cases patients received only 1 antibiotic for treatment of mild/moderate pneumonia.

\section{Pharmacy dispensing practices}

The quality of the patient information about drug use was measured using 2 indicators, quality of drug labelling and patient knowledge (Table 4). The correct drug labelling criteria for prescriptions (drug name, dosage and expiry date) were met in $84 \%$ of the prescriptions on average. The criteria for adequate patient knowledge about the dispensed drugs (able to recognize the drug, its indication and use) were met for only for $60 \%$ of patients, and this was low in Khorasan (38\%) compared with Tehran $(84 \%)$.

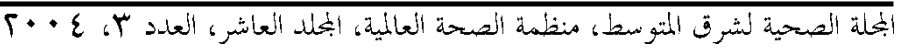




\begin{tabular}{|c|c|c|c|c|c|c|}
\hline \multicolumn{6}{|c|}{ Eastern Mediterranean Health Journal, Vol. 10, No. 3, 2004} & \multirow[t]{2}{*}{411} \\
\hline $\begin{array}{l}\text { Table } 3 \text { Prescribing indicat } \\
\text { Islamic Republic of Iran }\end{array}$ & ors for trea & ent of 3 & $\operatorname{mon} c$ & nditions in 5 & provinces of & \\
\hline Indicator $^{a}$ & Khorasan & Tehran & Fars & Khozestan & Kermanshah & $\begin{array}{l}\text { National } \\
\text { average }\end{array}$ \\
\hline \multicolumn{7}{|l|}{ Diarrhoea } \\
\hline Oral rehydration salts (\%) & 61 & 68 & 73 & 11 & 61 & 57 \\
\hline Antibiotic (\%) & 67 & 64 & 64 & 49 & 67 & 64 \\
\hline Antidiarrhoeal (\%) & 14 & 39 & 19 & 5 & 13 & 19 \\
\hline Antispasmodic (\%) & 62 & 43 & 48 & 70 & 68 & 59 \\
\hline Other drugs (\%) & 59 & 27 & 48 & 76 & 62 & 53 \\
\hline \multicolumn{7}{|l|}{$\begin{array}{l}\text { Acute/upper respiratory } \\
\text { tract infection }\end{array}$} \\
\hline Antibiotic (\%) & 69 & 81 & 64 & 87 & 79 & 77 \\
\hline Antipyretic/analgesic (\%) & 67 & 76 & 76 & 70 & 77 & 73 \\
\hline Cough/cold drugs (\%) & 83 & 60 & 81 & 75 & 88 & 78 \\
\hline Other drugs (\%) & 54 & 60 & 49 & 47 & 39 & 49 \\
\hline \multicolumn{7}{|l|}{ Mild/moderate pneumonia } \\
\hline Procaine penicillin (\%) & 55 & 75 & 26 & 20 & 20 & 35 \\
\hline Amoxicillin (\%) & 47 & 25 & 82 & 55 & 47 & 50 \\
\hline Co-trimoxazole (\%) & 10 & 18 & 40 & 24 & 28 & 21 \\
\hline \multicolumn{7}{|l|}{ Other antibiotics (\%) } \\
\hline 0 & 73 & 100 & 88 & 78 & 71 & 77 \\
\hline 1 & 25 & 0 & 8 & 8 & 21 & 17 \\
\hline$>1$ & 2 & 0 & 4 & 14 & 8 & 6 \\
\hline Antipyretic/analgesic (\%) & 78 & 58 & 82 & 93 & 85 & 84 \\
\hline Cough/cold drugs (\%) & 84 & 58 & 64 & 75 & 90 & 81 \\
\hline Other drugs (\%) & 48 & 0 & 40 & 41 & 34 & 33 \\
\hline
\end{tabular}

avalues shown are percentage of prescribed medicines for the condition.

\section{Availability of basic information in facilities}

Table 5 shows that the availability of the national treatment guidelines was high in most provinces ( $91 \%$ on average), whereas the Iranian national drugs list was present in only $6 \%$ and $10 \%$ of primary care centres in Khozestan and Kermanshah provinces respectively.

\section{Assessment of private pharmacies and warehouses}

A rapid assessment of private pharmacies and regional drug warehouses showed prices and affordability for different drugs were the same in public and private pharmacies. The number of expired drugs was very low in the private outlets $(1.2 \%)$. The situation in the warehouses was also good, with high drug availability, 94\% (lower in Kermanshah province), short average stock-out duration (6.6 days per year) and good quality of storage conditions (9.6 out of 11).

\section{Discussion}

The WHO level 2 indicators enable the evaluation of several aspects of the pharmaceu-

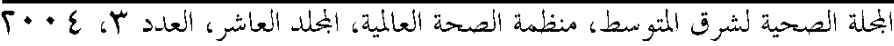




\begin{tabular}{lccccc}
\hline \multicolumn{6}{l}{ Table 4 Pharmacy dispensing indicators in 5 provinces of the Islamic Republic of Iran } \\
\hline Indicator & Khorasan & Tehran & Fars & Khozestan Kermanshah National \\
average
\end{tabular}

a Labelled with drug name, dosage and expiry date.

${ }^{b}$ Patient able to recognize the drug, its indication and use.

tical sector such as patients' access to drugs of good quality, rational prescribing and dispensing, availability of reference information in the primary care settings as well as the quality of drug warehouses and private pharmacies.

The availability of essential drugs in the primary health centre pharmacies was good and on average $92 \%$ of drugs on the list were available at the facility. This is confirmed by the finding that on average $95 \%$ of the drugs prescribed by the physician were dispensed by the health centre pharmacy. Stocks of essential drugs were also satisfactory and no drug on the list was unavailable for more than 1 month on average. The very low quantity of expired drugs (only 2/100 centres had more than 1 expired drug on their shelves) and the good quality of their storage (average score 8.4 on a scale from 0 to 11 ) confirm the quality of the pharmaceutical storage systems.

Affordability of drugs was also good. Our study showed that a complete course of treatment for pneumonia cost on average only $2 \%$ of the lowest weekly government salary. It should be also mentioned that for the $85 \%$ of the population covered by health insurance only $30 \%$ of the price has to be paid. The retail prices of amoxicillin powder for suspension and co-trimoxazole syrup are lower than the wholesaler prices reported by the International drug price indicator guide [4]. The costs of 3 generic drugs with identical price available across the country were as follows: procaine penicillin $(800,000 \mathrm{IU}$ injection) US\$ 0.11; amoxycillin (125 mg or

Table 5 Information availability indicators in primary health care facilities in 5 provinces of the Islamic Republic of Iran

\begin{tabular}{lcccccc}
\hline Indicator & Khorasan & Tehran & Fars & Khozestan Kermanshah National \\
average
\end{tabular}

$S T G=$ standard treatment guidelines .

$E D L=$ essential drugs list

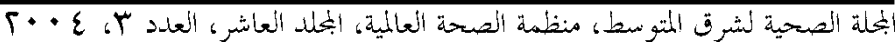


$5 \mathrm{~mL}$ of $100 \mathrm{~mL}$ suspension) US\$ 0.30 ; cotrimoxazole $(200 \mathrm{mg}+40 \mathrm{mg}$ per $5 \mathrm{~mL}$, $100 \mathrm{~mL}$ suspension) US\$0.33.

Physicians' prescribing habits showed that the average number of drugs prescribed per prescription was 3.4 overall. The number of drugs per prescription was lower in Tehran than other provinces. One possible explanation for this finding is the easier access to health care in the capital where people might visit the physician more often and have less complicated problems.

As in many other developing countries [7], use of antibiotics and injectable formulations was high in the Islamic Republic of Iran. The high number of prescriptions for antibiotics $(58 \%$ on average) may be because in the majority of the provinces, the data collected only covered a period of 1 winter month. In Fars province, the data were collected over a period of 8 months and $48 \%$ of prescriptions contained an antibiotic. This result might be closer to the actual annual average value. The prescription of injectable drugs was also very high ( $41 \%$ on average) but varied greatly between primary care centres. Apparently, patients and/or physicians still consider that injections are more effective than oral drugs. Further investigation is needed to understand the causes of high variability of injection prescribing among the different facilities. Examples of health centres with good prescribing habits should be studied and their strategies disseminated to the rest of the country.

The low adherence of physicians to standard treatment guidelines is disappointing, but we have some reservations about the collection of data. During the survey, it was sometimes difficult to link the prescriptions to the diagnosis because the prescribed treatment was not written in the logbook of the doctor (sometimes even the diagnosis was not recorded) and the prescriptions did not report the diagnosis. The most accurate result may be the one concerning the treatment of mild to moderate pneumonia, since the criterion for inappropriate prescribing pattern was the presence of more than 1 antibiotic on a prescription. Even in this case, one-third of the prescriptions were not in line with the existing standard treatment guidelines.

Pharmacy dispensing practices were also assessed. According to the survey criteria, the label of a drug was considered adequate if it stated the name, the dosage and the expiry date of the drug. These criteria were met in $84 \%$ of the monitored prescriptions on average. In Khorasan province, some investigators used stricter criteria: name of the drug, dosage, duration of therapy, time of intake (before or after the meal). For assessing patients' knowledge about the dispensed drugs, it was considered necessary that the patient should be able to recognize the drug, its indication and use for each drug delivered. On average, these criteria were met for only $60 \%$ of patients. If such a test is repeated, it would be interesting to stratify the answer according to the number of drugs prescribed. Low knowledge of the patients about their drugs indicates that pharmacists do not provide enough information to the patients.

The availability of the Iranian national treatment guidelines was good all over the country. However, the national drugs list was missing in the majority of the health centres in Khozestan and Kermanshah provinces. A repeated distribution of the drug list in these regions might be considered.

The survey included a rapid assessment of private pharmacies and regional drug warehouses. The price of drugs is fixed throughout the country and is the same in

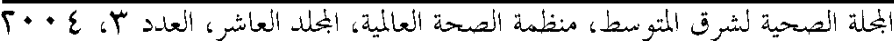


public and private pharmacies. The number of expired drugs was very low in the private outlets $(1.2 \%)$. The situation in the warehouses was also good, with high drug availability, short average stock-out duration and good quality of storage conditions.

\section{Conclusions}

\section{Strengths of the present system}

The survey confirmed the good availability of essential drugs in the public pharmacies. The management of drugs in these facilities is good, storage quality is up-to-standard, stock-out duration is acceptable, and levels of expired drugs were low. The system of centralized drug procurement and distribution contributed to these achievements. A $\mathrm{MOH}$ drug information service is actively providing information concerning the safe and rational use of drugs to health professionals and to the public $[5,6]$.

Affordability of drugs is very good; the very low drug price is the result of state support to the national pharmaceutical industry, which is highly subsidized. Furthermore, about $85 \%$ of the population is covered by one kind of health insurance, which pays $70 \%$ of the drug price. Compulsory generic prescribing and generic substitution guarantee a large use of generic drugs.

\section{Areas for improvement}

Drug availability in some regions of the country needs to be increased and stockout duration in some facilities should be reduced. Some training in management, effective procurement systems and organization of the public pharmacies should be considered in order to further decrease the drug stock-out duration in public health centres.
The recording procedures for diagnosis and treatment of patients are inefficient and do not allow a good follow-up of the prescribing patterns of the doctors. Patient diagnosis must be linked to patient treatment in order to allow an efficient monitoring of prescribing habits and to provide a reliable national disease pattern map. Both types of information should be at least recorded in the physician logbook. A better solution is to write the diagnosis (or its code) on the prescriptions. Pilot studies should be planned to demonstrate the utility of this procedure.

The knowledge of the patients concerning the drugs they received must be improved in order to guarantee a more rational use of medicines. Drug information booklets (e.g. explaining the rights of the patients or the rational use of antibiotics and injectables) should be prepared and disseminated. Media campaigns might also be considered. The cause of poor counselling by the pharmacists should be investigated with proposals for interventions. Written information should always be provided with all necessary details (name, dosage, duration of therapy, time of intake, expiry date) to assure a rational use of drugs. The newly developed repackaging system should be broadly implemented.

Further studies should be undertaken to understand better the reasons for the high rate of prescribing antibiotics and injections and the poor adherence to standard treatment guidelines by physicians. Appropriate administrative and educational strategies should be developed and implemented to improve prescribing habits. Subsidies to the pharmaceutical industry should be targeted in a way that does not lead to irrational drug use owing to the very low price of the drugs. 


\section{Acknowledgements}

This project was supported technically and financially by WHO/EDM and authors wish to thank specially Mr Indro Mattei for his valuable comments on the results.

\section{References}

1. Dinarvand R. Iran: an evolving national drug policy. Essential drug monitor, 1998, 22:9-10.

2. Operational package for monitoring and assessing country pharmaceutical situations. Geneva, World Health Organization, 2001. (http://www.who.int/medicines/strategy/policy/indicators op.shtml, accessed 19/09/04).

3. Pharmaceutical indicators and monitoring/assessment package, meeting 1-21 February 2003. Geneva, World Health Organization, 2003.

4. International drug price indicator guide. Boston, Massachusetts, Management Sciences for Health, 2001.

5. Nikfar S, Abdollahi M, Cheraghali A. Going from strength to strength-Iran's drug and poison information service. Essential drug monitor, 2000, 28/29:30-1.

6. Abdollahi M, Nikfar S. Three year report on Tehran Drug and Poison Information Centre. In: Proceedings of the VII World Conference on Clinical Pharmacology and Therapeutics, Division of Clinical Pharmacology, and 4th Congress of the European Association for Clinical Pharmacology and Therapeutics, Florence, Italy, 15- 20 July 2000:114.

7. van Staa A, Hardon A. Injection practices in the developing world. Results and recommendations from field studies in Uganda and Indonesia. Geneva, World Health Organization, 1996 (WHO/DAP/ 96.4).

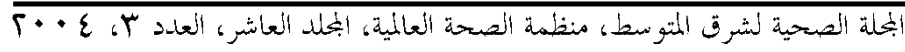

